\title{
STRATEGI BERSAING AGENCY MTHREE COMMUNICATION DALAM INDUSTRI PERIKLANAN NASIONAL
}

\author{
Linda Wardhani \\ Program Studi Magister Manajemen Universitas Tarumanagara \\ lindawardhani737@gmail.com \\ Eko Harry Susanto \\ Program Studi Magister Manajemen Universitas Tarumanagara
}

Masuk : 07-12-2019, revisi : 20-12-2019 diterima untuk diterbitkan : 20-12-2019

\begin{abstract}
Competition in the national advertising service industry is currently getting tougher, but the development potential of the advertising service industry is still quite good, especially in big cities that follow very rapid development. Advertising basically will never be lonely as seen from its function in introducing products that have effective and efficient usability properties, this of course makes more and more competitors also make the greater competition that will occur, if this is needed a business strategy that is able to compete. This research aims to determine whether the most appropriate strategy is used for Mthree Communication Advertising in the face of competition in the national advertising industry. This research was conducted in the Mthree Communication Advertising environment, with resource persons of employees who have strategic positions in the company's business and have a service life of more than 5 years. Research conducted using qualitative methods by conducting a SWOT analysis to identify strengths (weaknesses), weaknesses (weaknesses), opportunities (opportunities), and threats (threats). From the SWOT analysis, a SWOT matrix will be created which is useful for formulating alternative strategies for the company. From the results of the research that has been carried out, it has been concluded that the right competitive strategy for the company is the focus strategy, which is to provide maximum services to clients who are running until now.
\end{abstract}

Keywords : Competitive Strategy, Advertising Services Industry, SWOT

\begin{abstract}
Abstrak : Persaingan di dalam industri jasa periklanan Nasional saat ini semakin ketat, namun potensi perkembangangan yang dimiliki industri jasa periklanan masih cukup terbilang bagus, terutama di kota-kota besar yang mengikuti perkembangan yang sangat pesat. Periklanan pada dasarnya tidak akan pernah sepi sebagaimana dilihat dari fungsinya dalam mengenalkan produk yang memiliki sifat kegunaan yang efektif dan efisien, hal ini tentu saja menjadikan semakin banyak kompetitor yang juga menjadikan semakin besar persaingan yang akan terjadi, jika sudah begini dibutuhkan strategi bisnis yang mampu bersaing. Penelitian ini bertujuan untuk mengetahui strategi apakah yang paling sesuai digunakan untuk Mthree Communication Advertising dalam menghadapi persaingan di dalam industri periklanan Nasional. Penelitian ini dilakukan di lingkungan Mthree Communication Advertising, dengan nara sumber para karyawan yang memiliki posisi strategis dalam bisnis perusahaan dan memiliki masa kerja di atas 5 tahun. Penelitian yang dilakukan menggunakan metode kualitatif dengan melakukan analisis SWOT untuk mengidentifikasi kekuatan (strenght), kelemahan (weakness), peluang (opportunity), dan ancaman (threat). Dari analisis SWOT tersebut selanjutnya akan dibuat matriks SWOT yang berguna untuk merumuskan beberapa alternative strategi bagi perusahaan. Dari hasil penelitian yang terlah dilakukan disimpulkan bahwa strategi bersaing yang tepat bagi perusahaan adalah strategi fokus yaitu memberikan layanan secara maksimal kepada klienklien yang sedang berjalan sampai dengan saat ini.
\end{abstract}

Kata Kunci : Strategi Bersaing, Industri Jasa Periklanan, SWOT 


\section{PENDAHULUAN}

Periklanan (advertising) mengalami perkembangan pesat di Indonesia pasca reformasi politik tahun 1998. Sebab secara langsung nuansa kebebasan berkomunikasi yang dinikmati masyarakat, mendorong pembuatan iklan menjadi ekspresif dengan sentuhan kreativitas yang sesuai dengan dinamika tuntutan masyarakat (susanto, 2014 - Jurnal Dinamika Pesan Iklan). Dalam periklanan, sebuah iklan dari suatu produk memerlukan sebuah perantara untuk bisa mengiklankan produknya tersebut maka dari itu diperlukanlah perusahaan jasa periklanan atau Advertising Agency. Perusahaan periklanan sendiri merupakan usaha yang saat ini masih terus berkembang terlebih dengan semakin banyak produk-produk baru yang bermunculan dipasaran, Kondisi seperti ini tentunya menuntut perusahaan harus lebih kreatif dan inovatif dengan menawarkan produk atau jasa yang bernilai lebih dan juga harus bisa menunjukan difrensiasi guna menghadapi para pesaing. Michael E. Porter (2007) menyatakan bahwa "suatu perusahaan harus memiliki banyak kekuatan dan kelemahan dalam berhadapan dengan para pesaing.dan beberapa strategi bersaing yang dapat di kembangkan adalah Keunggulan Biaya, Diferensiasi, dan Fokus". Untuk tetap bertahan dalam persaingan bisnis diperlukan strategi bersaing yang tepat bagi sebuah perusahaan untuk tetap eksis, salah satunya ialah perusahaan Agency Mthree Communication Advertising dimana dalam menghadapi persaingan dalam industri periklanan. Selain itu jaminan pelayanan seperti pengalaman, harga yang kompetitif dari para pesaing dan juga service yang cepat guna memelihara hubungan baik dengan klien dan memberikan pelayanan yang dapat membuat klien merasa puas akan kerja yang dilakukan. Berdasarkan latar belakang diatas, maka penulis tertarik untuk melakukan penelitian dengan menarik judul "STRATEGI BERSAING AGENCY MTHREE COMMUNICATION ADVERTISING DALAM INDUSTRI PERIKLANAN NASIONAL".

Berdasarkan uraian dari latar belakang yang telah dijabarkan maka rumusan masalah pada penelitian ini yang akan dianalisis dalam penelitian ini antara lain: Bagaimana kondisi yang meliputi faktor-faktor internal perusahaan (kekuatan dan kelemahan) dan faktor eksternal perusahaan (peluang dan ancaman) yang dimiliki Mthree Communication Advertising dalam menghadapi persaingan di industri periklanan Nasional?

\section{LANDASAN TEORI}

Scott (2010) menyatakan strategi bersaing adalah sebuah rencana untuk bagaimana sebuah perusahaan akan bersaing, memformulasikan, dan mengevaluasi bagaimana kekuatan dan kelemahan perusahaan untuk berhadapan dengan kompetitornya. Menurut Dagmino (2012) strategi kompetitif Sedangkan menurut Porter (2001) strategi bersaing adalah mengembangkan rencana mengenai bagaimana bisnis akan bersaing, apa yang seharusnya menjadi tujuannya dan kebijakan apa yang diperlukan untuk mencapai tujuan tersebut. Di dalam analisa mengenai tentang strategi bersaing (competitive strategy) suatu perusahaan menyebutkan bahwa setiap perusahaan selalu menempatkan darinya pada salah satu aspek utama seperti yang Michael A. Porter kemukakan terdapat 3 macam strategi generic, yaitu: strategi keunggulan biaya (cost leadership), strategi perbedaan produk (diffrensiation), strategi fokus (focus)

Sifat dan derajat persaingan dalam suatu industri bergantung pada lima kekuatan atau dikenal dengan Model Lima Kekuatan Porter merupakan pendekatan yang digunakan secara luas untuk mengembangkan strategi dibanyak industri (David, 2011). Terdapat lima (5) kekuatan yang menjadi penyebab atau perpaduan yang menimbulkan persaingan, antara lain persaingan dalam pasar yang telah ada. Potensi masuknya pesaing baru, Potensi munculnya produk/barang subsitusi, Daya tawar pemasok, dan Daya tawar komsumen atau pembeli.

David (2015), matriks SWOT (Strenght, Weakness, Opportunity, Thread) merupakan perangkat pencocokan penting yang membantu manager mengembangkan empat tipe strategi yaitu: Strategi SO, Strategi WO, Strategi ST, dan Strategi WT. 


\section{METODOLOGI PENELITIAN}

Jenis penelitian yang digunakan yaitu penelitian kualitatif. Penelitian kualitatif ditunjukan untuk mengetahui sebab bagaimanan dan mengapa suatu masalah terjadi dalam suatu penelitian. Penelitian kualitatif sendiri mencangkup teknik interpretasi yang mendalami suatu masalah, sehingga dapat mendeskripsikan, mengartikan data, sehingga mencapai suatu kesimpulan, Cooper (2008). Subjek penelitian pada penelitian ini meliputi Direktur, Media, Marketing, Keuangan, Traffic, HRD yang memiliki masa kerja di atas 5 tahun. Sumber data kualitatif dapat dibedakan menjadi 2 yaitu data primer dan data sekunder. Data premier adalah data yang berupa teks hasil wawancara dan diperoleh melalui wawancara dengan informan yang dijadikan sampel dalam penelitiannya, data tersebut dapat direkam atau dicatat. Sedangkan data sekunder adalah data berupa data-data yang sudah tersedia dan dapat diperoleh dengan cara membaca, melihat dan mendengarkan. Data sekunder biasanya dari data bentuk teks, gambar, suara. (Sarwono, 2006).

\section{ANALSIS DAN PEMBAHASAN Gambaran Umum Perusahaan}

Mthree Communication Advertising adalah sebuah perusahaan skala menengah yang bergerak dalam bidang jasa dan konsultan yang menangani placement iklan yang bekerjasama dengan berbagai media elektronik, cetak dan media luar ruang. Tidak hanya placement iklan saja service yang diberikan oleh agency Mthree Communication Advertising, namun juga menyediakan jasa konsultan periklanan meliputi perencanaan budget, perencanaan iklan dll. Mthree Communication Advertising mengukuhkan diri sebagai perusahaan biro iklan dengan predikat agency all service yang menangani ATL (Above The Line) seperti placemement di media cetak, elektronik dan OOH, BTL (Below The Line) seperti event-event.

\section{Analisis SWOT}

\begin{tabular}{|c|c|c|}
\hline $\begin{array}{l}6 . \\
7 .\end{array}$ & $\begin{array}{l}\text { KEKUATAN (S) } \\
\text { Nilai Jual/positioning Perusahaan sebagai agency all } \\
\text { service } \\
\text { Citra perusahaan yang sudah terbentuk lama sebagai } \\
\text { perusahaan periklanan yang baik (dimata klien dan } \\
\text { vendor. } \\
\text { Pelayanan memuaskan yang diberikan baik secara } \\
\text { professional maupun personal } \\
\text { Infrastruktur bisnis yang dimiliki perusahaan cukup } \\
\text { lengkap (media spesialis, creative agency, editing, } \\
\text { brand activation, PH, dll) dengan harga bersaing. } \\
\text { Memiliki sistem kerja yang fleksibel dari segi waktu } \\
\text { yang terbatas sekalipun } \\
\text { Team kreatif yang berpengalaman dibidangnya } \\
\text { Karakter klien yang berorientasi pada target penjualan } \\
\text { dan memiliki sifat loyal }\end{array}$ & $\begin{array}{ll}\text { KELEMAHAN (E) } \\
\text { 1. } \\
\text { Brand perusahaan yang kurang dikenal oleh calon } \\
\text { klien karena merupakan agency lokal } \\
\text { 2. Output yang dihasilkan team creative masih terlalu } \\
\text { lemah dalam pengembangan ide } \\
\text { 3. Pusat pengambilan keputusan bisnis masih di pegang } \\
\text { oleh Top Management (Dirut) } \\
\text { 4. Keputusan perusahaan yang menempatakan klien pada } \\
\text { posisi sedemikian kuat menjadi kendala tersendiri } \\
\text { dalam operasional } \\
\text { 5asih sedikitnya klien baru yang masuk dikarenakan } \\
\text { merasa cukup dengan dengan klien lama yang masih } \\
\text { existing }\end{array}$ \\
\hline 6. & $\begin{array}{l}\text { PELUANG (O) } \\
\text { Perkembangan industri periklanan yang diukur dari } \\
\text { data besaran belanja iklan } \\
\text { Trend industri periklanan khususnya TV yang mulai } \\
\text { berkembang ke arah built in program maupun creative } \\
\text { media item } \\
\text { Perkembangan media consumtion dari media } \\
\text { tradisional ke digital melahirkan bentuk-bentuk iklan } \\
\text { sebagai alternatif media promosi } \\
\text { Semakin banyak munculnya brand dan produk-produk } \\
\text { baru yang dibarengi dengan kebutuhan promosi } \\
\text { Semakin banyak munculnya brand dan produk-produk } \\
\text { baru yang dibarengi dengan kebutuhan promosi } \\
\text { Adanya rasa puas klien terhadap kinerja perusahaan } \\
\text { dibarengi dengan penilaian positif yang diberikan klien } \\
\text { tiap tahunnya }\end{array}$ & $\begin{array}{l}\text { ANCAMAN (T) } \\
\text { 1. Dampak dari ketidakstabilan politik dalam negeri } \\
\text { mengakibatkan labilnya nilai tukar rupiah terhadap } \\
\text { dolar yang berdampak pada penurunan daya beli } \\
\text { masyarakat yang berimbas pada budget promosi } \\
\text { 2. Kemajuan dibidang teknologi komunikasi dan } \\
\text { informasi berbasis internet yang selama ini kurang } \\
\text { diperhitungkan } \\
\text { 3. Klien yang makin cerdas dan data minded } \\
\text { menyebabkan semakin selektif terhadap pengeluaran } \\
\text { budget promosi dan pemilihan media } \\
\text { 4. Perubahan dan permintaan arah kebutuhan promosi } \\
\text { klien yang makin kompleks } \\
\text { Gaya hidup masyarakat yang selalu berubah mengikuti } \\
\text { trend, diikuti perubahan kebutuhan dan keinginan } \\
\text { konsumen sebagai end user }\end{array}$ \\
\hline
\end{tabular}




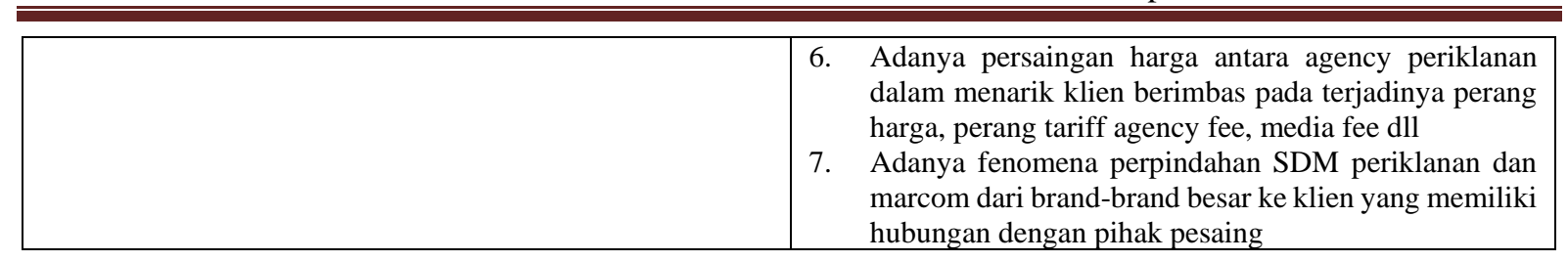

Berdasarkan Matriks SWOT di atas maka berikut adalah strategi yang dapat digunakan perusahaan:

Strategi S-O

1. Mengembangkan keahlian dalam membuat konsep dan strategi creative media dilihat dari sisi nilai manfaat dan juga efektifitasnya sebagai bentuk alternative promosi klien (S4, S5, O2)

2. Meningkatkan mutu serta fokus pada program komunikasi perusahaan yang berfungsi manarik calon klien-klien baru potensial ( $\mathrm{S} 1, \mathrm{~S} 2, \mathrm{~S} 4, \mathrm{~S} 6, \mathrm{O} 3, \mathrm{O} 4)$

3. Menitik beratkan pada pengembangan konsep metodologi pemasaran dan juga periklanan yang disesuaikan dengan tuntutan kebutuhan pasar (S4, S5, O3, O4)

4. Memaksimalkan kekuatan internal perusahaan dalam mengikuti proyek-proyek campaign berbagai instasi baik pemerintah maupun swasta (S3, S4, S5, S6, O5)

Strategi W-O

1. Mengembangkan strategi pemasaran perusahaan periklanan yang bertujuan untuk menyebarkan informasi jika perusahaan Mthree Communicatin Ageny Advertising adalah sebagai perusahaan periklanan all service yang dapat memenuhi segala kebutuhan bentuk promosi klien (W1, O1, O2, O5)

2. Melakukan pembaruan kemampuan tim kreatif dalam kegiatan penyusunan strategi pengembangan promosi merek klien yang lebih sistematik (W2, W5, O3, O4, O5)

3. Membuat suatu kebijakan perusahaan yang tujuannya untuk mengatur porsi dan tanggung jawab serta wewenang para anggota top management (W3, W4, O1, O2, O4, O5)

Strategi S-T

1. Optimalisasi fungsi kerja dalam strategi pengembangan pasar baik itu dalam pemilihan media, kreatif yang bertujuan agar lebih efektif dan efisien (S4, S5, S6, T1, T2, T5, T6)

2. Melakukan perencanaan anggaran organisasi yang bertujuan untuk efisiensi biaya operasional seperti pengembangan materi kreatif serta biaya produksi yang semuanya dibebankan kepada klien (S3, S4, T1, T3, T6)

3. Memperkuat sistem perlindungan klien secara menyeluruh oleh perusahaan dan menjadikan Mthree Communication sebagai perusahaan periklanan yang siap dengan perubahan (S1, S2, S3, S7, O7)

Strategi W-T

1. Mengembangkan kebijakan kerjasama kegiatan bisnis belanja media dan program komunikasi pemasaran dengan perusahaan lain yang lebih kuat (W1, W2, T2, T3, T4, T5)

2. Membuat kebijakan yang lebih pro karyawan yang bertujuan mensejahterakan, adanya jenjang karir dan pendapatan serta kenyamanan dalam lingkungan kerja (W3, W4, T7)

Strategi W-O

1. Mengembangkan strategi pemasaran perusahaan periklanan yang bertujuan untuk menyebarkan informasi jika perusahaan Mthree Communicatin Ageny Advertising adalah sebagai perusahaan periklanan all service yang dapat memenuhi segala kebutuhan bentuk promosi klien (W1, O1, O2, O5)

2. Melakukan pembaruan kemampuan tim kreatif dalam kegiatan penyusunan strategi pengembangan promosi merek klien yang lebih sistematik (W2, W5, O3, O4, O5) 
3. Membuat suatu kebijakan perusahaan yang tujuannya untuk mengatur porsi dan tanggung jawab serta wewenang para anggota top management (W3, W4, O1, O2, O4, O5)

\section{KESIMPULAN DAN DARAN \\ Kesimpulan}

Berdasarkan data hasil nanlisis dan pembahasan yang telah dilakukan, dapat disimpulkan bahwa:

1. Strategi pemasaran berbasis kekuatan-peluang, meliputi menguatkan konsep dari sisi pengembangan creative media placement, memfokuskan program komunikasi perusahaan dalam hal lebih memperkenalkan secara luas brand perusahaan, mengembangkan konsep pemasaran periklanan, Melakukan pola kerja yang bersinergi terhadap perusahaan.

2. Alternatif sinergi berbasis kekuatan-ancaman, seperti optimalisasi fungsi kerja dalam strategi pengembangan pasar, melakukan perencanaan anggaran yang bertujuan untuk efisiensi biaya operasional, memperkuat sistem perlindungan klien secara menyeluruh

3. Alternatif sinergi berbasis kelemahan-ancaman, yaitu mengembangkan kebijakan kerjasama dengan perusahaan dalam program komunikasi pemasaran, membuat kebijakan yang lebih pro karyawan.

4. Alternatif sinergi berbasis kelemahan-peluang, meluputi mengembangkan strategi pemasaran guna memperkenalkan brand perusahaan, melakukan pembaruan kemampuan tim kreatif, membuat suatu kebijakan untuk mengatur porsi wewenang para anggota top Saran management.

Melakukan pendekatan dengan cara yang profesional dan juga personal kepada semua klien Mthree Communication Advertising agar lebih dapat mengetahui kebutuhan, keinginan dan juga harapan klien melalui pengembangan kompetensi SDM yang dimiliki perusahaan, baik itu dari sisi team kreatif, team media serta team marketing dan sales dan juga yang lainnya. Mengoptimalkan bentuk program pemasaran yang akan dijalankan Mthree Communication Advertising dalam memperkenalkan perusahaan pada pasar yang luas, sehingga brand perusahaan sebagai agency periklanan all service dapat diketahui oleh klien-klien, khususnya klien baru, serta selalu melakukan monitoring dan juga evaluasi terhadap berbagai pelaksanaan berbagai kegiatan proyek pengerjaan agar lebih dapat mengetahui hasilnya secara maksimal melalui feedback dan penilaian langsung yang diberikan klien.

\section{DAFTAR PUSTAKA}

Cooper. (2008). Business Research Methods. Singapore : McGraw Hill.

Dagimo, Giovanni B. (2012). Handbook of Research on Competitive Strategy. Cheltetam: Edward Elgar Publishing Limited.

David, Fried R. (2015). Strategic Management : Cocepts and Cases, Boston: Pieson, c2015 (Global edition). ISBN: 9780133444797.

David, Fried R. (2011). Strategic Management Cocepts and Cases, Thirteenth Edition. New Jersey: Prentice Hall.

Jonathan, Sarwono. 2006. Metode Penelitian Kuantitatif dan Kualitatif. Yogyakarta: Graha Ilmu.

Porter, Michael, E. (2007). Strategi Bersaing (Competitive Strategy). Tangerang: Karisma Publishing Group.

Porter, Michael, E. (2001). Strategi Bersaing, Teknik Menganalisa Industri dan Pesaing. Erlangga. Jakarta.

Scott, D. L. (2010). American Heritage Dictionary of Business Term. Boston: Hugton Miifflin.

Susanto, Eko Harry. Dinamika Pesan Iklan. Universitas Tarumanagara. 2014 